\title{
The Jurisdiction of Justice: Two Conceptions of Political Morality
}

\author{
LARRY ALEXANDER*
}

My topic in this essay is a major fault line within normative theory. More precisely, it is a major fault line within that part of a normative theory that deals with the content of our moral obligations to others. ${ }^{1}$ When I refer to moral obligations here, I am referring to those acts that morality demands of us such that it permits force or its threat to be employed to secure those acts. Moral obligations, as I use the term, are thus candidates for legal enforcement.

I argue that much of what is debated within liberal political/moral theory can be usefully illumined by dividing liberal conceptions of justice into two major camps. In one camp are those conceptions that are thoroughgoingly impartialist. That is, their impartialism applies to any good over which people might make competing claims. I shall refer to this group of conceptions as Unrestricted Impartialism, or UI.

Opposed to this camp of liberal conceptions of justice is that group of

* Warren Distinguished Professor of Law, University of San Diego. I wish to thank the following: Richard Arneson, Steve Smith, and Chris Wonnell, for their comments; Jacinda Lanum for her research; Sara Moore for her typing; and Dean Daniel Rodriguez for a generous summer research stipend.

1. I shall thus not be discussing many other aspects of moral theory. For example, I leave aside the entire field of metaethics, which deals with such matters as: To what do moral claims refer? Are they objective, and in what sense? How do they connect with facts in the world as science perceives them-are they constituted by, do they supervene upon, or are they identical to such facts? What is the connection between morality and reason? And what is the relation among morality, reason, and our motivational sources? Nor shall I be dealing with such metaphysical/moral relationships as how free will and determinism bear on moral responsibility. Finally, there are normative questions about virtue, about supererogation, and about nonenforceable "moral oughts" that I am not concerned with here. 
conceptions that limits impartialism to some goods but puts other goods beyond the writ of justice (enforceable morality). I shall call this group of conceptions Restricted Impartialism, or RI.

In this essay, my aim is to paint these two conceptions and their strengths and weaknesses using a very broad brush. In philosophy, the devil is more frequently than not in the details, and broad brush strokes generally obfuscate more than illuminate. Moreover, my métier tends to be fine analytical points and not big picture tableaux. Nonetheless, not only do space limitations preclude in-depth analyses of the conceptions I discuss, but my message is a wholesale rather than a retail one, namely, that there is a single and major gulf dividing liberal conceptions of justice into these two distinct camps. Analytical fine points about these conceptions are beside the point.

\section{UNRESTRICTED IMPARTIALISM}

UI conceptions of justice operate with no restriction on their domain. That is, UI conceptions render any good eligible for distribution according to whatever conception of impartiality is chosen.

UI conceptions differ among themselves along two axes. First, they differ over whether goods should be distributed to maximize something, to equalize it, or to prioritize some beneficiaries of it relative to others, and over how the recipients' responsibility for these circumstances and their virtues and vices should affect their distributive shares. That is, these conceptions differ along this axis of distributional formulae. ${ }^{2}$

The second axis along which these conceptions differ is the axis of what is to be distributed in pursuance of the chosen distributional formula. Is it welfare, opportunity for welfare, capabilities, resources, Rawlsian primary goods, or some objective list of goods that should be maximized, equalized, and so on? In other words, what is the currency that we are to distribute impartially?

The distributional formulae and currency debates make up a substantial portion of the philosophical treatment of UI. They are not my present concern, however, so I set their important and interesting issues aside. Of more relevance to my topic here is a set of problems that bedevil all UI conceptions of justice, no matter how different they otherwise are from one another.

The first problem is that of natural partiality toward kith and kin.

2. See generally Richard J. Arneson, Luck Egalitarianism and Prioritarianism, 110 ETHICS 339 (2000); G. A. Cohen, On the Currency of Egalitarian Justice, 99 ETHICS 906 (1989); Ronald DwOrkin, Sovereign VIRTUE Chs. 2, 7 (2000); Kasper LippertRasmussen, Egalitarianism, Option Luck, and Responsibility, 111 ETHICS 548 (2001); ERIK RAKOWSKI, EQUAL JUSTICE 17-183 (1991). 
People generally place the welfare of their families, friends, close associates, neighbors, and countrymen above that of distant strangers. Yet the UI stance on its face conflicts with such forms of partiality. ${ }^{3}$ Because lives without the attachments that foster partiality appear stunted and less than fully human, the problem of natural partiality poses a severe threat to UI theories of justice.

A second problem for UI theories of justice is that of self-effacement, a problem that is central to Bernard Williams's criticisms of UI. ${ }^{4}$ Under UI, our attitude toward our life's projects - those activities and commitments that invest our lives with meaning and value - must be a detached one. We must be prepared to jettison any and all such projects whenever our pursuit of them becomes inconsistent with maximizing, equalizing, prioritizing, or maximining whatever UI tells us to maximize, equalize, prioritize or maximin. The moral propriety of our projects is always contingent on the latest returns from the UI distributional formula calculus.

Or, put differently, according to UI, we can only have one project to which we are psychologically attached, namely, to distribute goods that are UI currency according to UI distributional formulae. All more specific projects are in service of and hostage to that master project.

The self-effacement problem can be viewed as but a more general version of the natural partiality problem. Our "projects" toward which we are partial include family, friendship, patriotism, and so forth, as well as our vocation, hobbies, causes, and the like.

A third problem for UI theories is that of demandingness. UI theories may require huge sacrifices of us. ${ }^{5}$ Utilitarianism, a UI theory, might

3. See, e.g., Thomas Nagel, Equality and Partiality 10-20 (1991); Samuel SChEFFler, Boundaries AND Allegiances: Problems of Justice AND RESPONSIBILITY IN LiBerAL THOUGHT 97-110 (2001). Richard Arneson believes that partiality towards kith and kin is reconcilable with UI, though it does entail dispositions to do wrong (violate UI morality). See Richard J. Arneson, Consequentialism vs. Special-Ties Partiality, 86 The Monist 382 (2003). See also Robert F. Card, Consequentialism, Teleology, and the New Friendship Critique, 85 PAC. PHIL. Q. 149 (2004) (arguing that friendship and consequentialism are fully compatible). Garrett Cullity takes the view that UI entails the permissibility of partiality. See Garrett Cullity, Asking Too Much, 86 THE MONIST 402 (2003). And for a recent attempt to reconcile UI with partiality towards friends, see Card, supra.

4. Bernard Williams, A critique of utilitarianism, in J.J.C. SMART \& BERNARD Williams, Utilitarianism: For and Against 77, 77-150 (1973). See also SAmuel Scheffler, The ReJeCtion of CONSEQuentialism 7-10 (1982); Samuel Scheffler, Doing and Allowing, 114 ETHICS 215 (2004).

5. See, e.g., Shelly Kagan, The Limits of Morality 233-41 (1989); Bashshar 
demand that some people sacrifice everything - their lives, their families, all their wealth - if doing so will somehow maximize aggregate welfare. This is, indeed, a standard criticism of utilitarianism, namely, that it might permit some to be sacrificed for the good of the whole. But all UI theories have this demandingness problem. Equalizing welfare, for example, given some people's seriously impaired ability to convert resources into welfare, may require huge and impoverishing transfers of resources to those people. Moreover, any plausible version of equality of resources, primary goods, or objective list goods would count such capabilities as, for example, good health as UI currency. But it is possible that some people's health can be brought up to a level of equality only by redistributing resources in their direction to such an extent that everyone is left impoverished.

As with the relation between the self-effacement problem and the natural partiality problem, the demandingness problem can be viewed as a more general version of the first two. Giving up one's attachments and one's projects may be just instances of UI's demandingness and on a par with giving up most of one's resources.

The fourth and final problem of UI theories of justice is that of nonrecognition of rights. A simple example will illustrate this problem, which is endemic to all UI theories. Suppose A has two healthy kidneys, and $\mathrm{B}$ is facing the prospect of kidney failure. And suppose that we can remove one of A's kidneys with little discomfort or risk to A and save B's life by transplanting it in him. Finally, suppose that doing this will maximize, equalize, etc. whatever currency the UI theory tells us to maximize, equalize, etc. Under UI, A can have no valid objection to the harvesting of his kidney. He has no right to his kidney that can trump the UI distributive formula. His body, his labor, and his talents are not his in any sense that would connote that he has a right to them that would protect them from a UI-dictated redistribution. That is what I mean when I say that UI theories have a problem of nonrecognition of rights.

The nonrecognition of rights problem is related to the preceding three problems in the following way: If people had rights over their bodies, labors, and talents, rights that were strong enough to trump the UI distributional formula, then they might have moral space within which they could display partiality toward persons and projects and accumulate resources that were not subject to redistribution.

Haydar, The Moral Relevance of Cost, 112 PHIL. STUD. 127, 127-34 (2003); Shelly Kagan, Does Consequentialism Demand Too Much? Recent Work on the Limits of Obligation, 13 Phil. \& Pub. Aff. 239, 239-40 (1984); Tim Mulgan, The Demands of CONSEQUENTIALISM (2001); SCHEFFLER, supra note 4; Peter Singer, Famine, Affluence, and Morality, 1 PHIL. \& PuB. AfF. 229, 238-39 (1972). 
Proponents of UI theories employ different strategies for handling these four problems. One strategy directed at the first two problems is to advocate a public/private distinction and then relegate UI to the public side, leaving individuals acting in their private capacities to be as partial as they wish toward people and projects. ${ }^{6}$ This strategy is, I believe, unsuccessful. For one thing, I am highly doubtful that a line can be drawn between public and private in a way that is defensible as a matter of moral theory. Government is not some sort of natural moral kind that is morally discontinuous from the individuals who elect it and run it; it is, therefore, quite difficult to justify "UI for government, partiality for individuals." Moreover, this strategy cannot even begin to cope with partiality toward one's countrymen, given the absence of a global government to fill the UI role. Finally, this strategy, even if it were successful in handling the problems of partiality, is not equipped to handle the problems of demandingness and nonrecognition of rights.

Samuel Scheffler attempts to handle the first three UI problems by dropping strict impartiality and allowing each person to give his own interests - including family, friends, causes, and so forth - extra weight in the UI calculus. ${ }^{7}$ The problems with his approach have been extensively chronicled elsewhere. ${ }^{8}$ For one, his approach would lead to radically conflicting permissions, given that A can give his own welfare $\mathrm{X}$ times the weight that he must give B's welfare, and B can give his welfare $\mathrm{X}$ times the weight that he must give A's welfare. Unless those permissions are supplemented by rights that block actions that are otherwise permitted, Scheffler's weighted partiality theory will be incoherent. But Scheffler wants to reject rights because he cannot understand why rights may not be violated even to prevent a greater loss of the interests rights protect. (And "rights" that may be so violated are not really rights. $)^{9}$

An alternative approach to UI's problems is advanced by Douglas

\footnotetext{
(1995).

6. See, e.g., Robert E. Goodin, Utilitarianism as a Public Philosophy 61

7. See SCHEFFLER, supra note 4

8. See, e.g., Larry A. Alexander, Scheffler on the Independence of AgentCentered Prerogatives from Agent-Centered Restrictions, 84 J. PHIL. 277, 278-83 (1987).

9. It is arguable whether Scheffler is even a UI theorist, given that he allows for partiality. I place him there primarily because he rejects rights and accepts consequentialism. He is therefore clearly not an RI theorist. Perhaps he defies categorization within any schema. I mention him only to show that he provides the UI proponents no lever for overcoming the four problems.
} 
Portmore. ${ }^{10}$ Portmore handles them by driving a wedge between what morality requires and what is rational. Most moral theorists, because they consider moral reasons to be overriding ones, do not accept any gap between reason and morality. Portmore, however, is willing to accept that what morality requires of one is something that would be on balance irrational (against the balance of reasons). Thus, UI moralists may dictate that we treat a stranger's welfare or projects as of equal importance to that of our children's welfare or our own projects, but the balance of reasons may favor our being partial to our children and projects.

Portmore's divorce of moral reasons from the balance of reasons, even if otherwise plausible, nonetheless cannot eliminate all of UI's problems. It is offered as a solution to the problems of demandingness and its lesser included problems of self-effacement and natural partiality. And it may succeed in solving them, though at the steep price of stripping morality of overridingness. Portmore in essence argues that reason, but not morality, tracks (inversely) demandingess. The more sacrifice an act requires of one, the less one has reason to do it.

However, Portmore's approach does not solve the problem of nonrecognition of rights. That is because the nonrecognition of rights problem is not a problem of demandingness. Giving up one's kidney may turn out to require very little sacrifice in terms of physical discomfort, loss of time, or increased risk. If reason ruled out even that degree of sacrifice, morality would hardly ever outweigh self-interest in practical reasoning. So Portmore should conclude that both morality and reason can require people to use their bodies, labors, and talents to benefit others, as UI theories prescribe. And this means that the nonrecognition of rights problem is untouched by Portmore's clever handling of demandingness problems. ${ }^{11}$

The most common way UI proponents attempt to deal with the four objections is the familiar one of distinguishing between the end states that their theories deem valuable and the decision procedures by which we attempt to achieve those end states. In other words, UI theorists adopt two-level, indirect consequentialist approaches. Thus, although our desideratum is a world in which everyone has X share of Y good-where $\mathrm{X}$ represents the preferred UI distributional formula and Y represents the

10. See Douglas W. Portmore, Position-Relative Consequentialism, AgentCentered Options, and Supererogation, 113 ETHICs 303, 303-32 (2003); Douglas W. Portmore, Commonsense Morality and Not Being Required to Maximize the Overall Good, 100 PHIL. STUD. 193, 193-213 (2000).

11. Nor does contractualism handle the nonrecognition of rights problem, a point ably demonstrated by Jeffrey Brand-Ballard in Contractualism and Deontic Restrictions, 114 ETHICS 269 (2004). 
preferred UI currency - we will achieve such a world, or come as close as we can to achieving it, only if we do not attempt to achieve it in every act we undertake. Perhaps we should go ahead and act with partiality toward kith and kin, with wholehearted devotion to our projects, and with a reluctance to be overly self-sacrificing. Perhaps we should attribute to others rights that trump the outcomes of the UI calculus. And perhaps we should inculcate dispositions in our children (and ourselves) to be devoted to kith, kin, projects, and rights. In other words, perhaps we can better achieve UI-preferred outcomes indirectly than directly.

There is, again, extensive literature on indirect or two-level consequentialism. ${ }^{12}$ My own contributions to that literature, although they support the critique of direct, or act-consequentialism, nonetheless point out significant theoretical, as well as practical, difficulties with indirect or two-level consequentialism. ${ }^{13}$

I am even more skeptical about indirect consequentialism as a solution to the nonrecognition of rights problem. First, the rights that indirect consequentialist maneuvers generate are not metaphysically anchored. They are merely strategies for achieving extrinsic goals. Second, and relatedly, their content will vary with circumstances. They will have different content in different places, in different historical periods, and in the presence of different technologies. That is not to say that they will differ isomorphically with circumstantial changes, for then indirect consequentialism would become direct (act-) consequentialism. They will differ to some degree, however, whenever the circumstantial changes are significant. Thus, to take an example, a right to favor one's neighbors might be the best UI strategy in a world in which people know very little about the circumstances of non-neighbors. As technology reduces the gap between knowledge about those nearby and knowledge about those far away, a right to favor one's neighbors may become suboptimal for achieving UI-sought end states.

Most importantly, however, there is no reason to believe that indirect consequentialist reasoning will produce precisely that set of rights that will solve the four problems. The indirect consequentialist solutions to these problems typically have the quality of "just so" stories or

12. See, e.g., the various contributions in MoRALITY, Rules, AND CONSEQUENCES: A CRITICAL READER (B. Hooker et al. eds., 2000).

13. See Larry AleXander \& Emily Sherwin, The Rule of Rules 53-96 (2001); Larry Alexander, Pursuing the Good-Indirectly, 95 ETHICS 315, 315-32 (1985). 
promissory notes: "We'll show you later how the correct set of indirect consequentialist rights for producing UI-sought end states just is the set that permits partiality, avoids demandingness, and protects people's bodies, labor, and talent against appropriation, but right now, just take our word that it does." I find it doubtful, however, that a convincing indirect consequentialist story can be told to explain on UI grounds, why a right should be recognized, say, against the nonvoluntary but safe, painless, and minimally time-consuming removal of a kidney to save another's life. ${ }^{14}$

In the end, I think that the four problems for UI theories remain unsolved. And because these problems are common to all UI theories, and are serious enough to discredit all UI theories, it is worthwhile to examine RI theories to see if they offer a palatable alternative to UI theories.

\section{RESTRICTED IMPARTIALITY}

RI theories of justice differ from UI theories in the following way: Whereas under UI theories all resources are in principle subject to the UI distributive formulae, under RI theories, the impartial formulae have a jurisdictional limit; they do not extend to persons' bodies, labor, or talents (unless those persons consent). Or, put differently, persons' bodies, labor, and talents are not resources to be distributed according to some conception of impartiality in the way that land, water, rights to act, and so forth are up for distribution. In RI theories, UI formulae have a restricted jurisdiction. ${ }^{15}$

RI theories account for why we might claim a right to resist kidney transplantation, even if the discomfort, the disruption of our life, and the risk were minimal and the transplantation would maximize, equalize, prioritize, etc. welfare, opportunities for welfare, resources, capabilities, or whatever else UI dictates. One's kidneys are not a resource up for UI redistribution. They are beyond its jurisdiction. Our enforceable obligations to others are limited to those domains in which we interact in

14. A desperate tactic that UI proponents sometimes resort to is to make rights into goods that the UI theory seeks to realize. I doubt the coherence of such a tactic. But even on its own terms, it does not explain why those rights may not be violated for the purpose of minimizing rights violations. (The "utilitarianism of rights" issue). The UI proponent might fall back on a claim that rights against such rights violations are also UI goods, but that would just raise the question of why not allow right violations to minimize violations of those secondary rights, ad infinitum.

15. This jurisdictional distinction between UI and RI theories is quite similar to the position taken by Eric Mack that rights establish jurisdictions of agent-control. See Eric Mack, In Defense of the Jurisdiction Theory of Rights, 4 J. ETHICS 71, 92-98 (2000); see also Keith Burgess-Jackson, Deontological Egoism, 29 Soc. THEORY \& PraC. 357, 35785 (2003). 
ways that threaten to make others worse off than had we not existed. Those obligations do not extend to those domains where our existence enables others to better themselves (over how they would fare in our absence) at our expense.

The basic norm of all RI theories is the norm against appropriation - taking another's bodies, labor, or talents without her consent. RI theories distinguish between what one perhaps morally ought to do and what can be morally demanded of one. Not everything that would maximize, equalize, prioritize, etc. can be demanded as opposed to requested.

The norm against appropriation explains the right against kidney transplantation, even when the transplantation will cause minimal harm to the kidney's possessor and greatly benefit the recipient. And it leaves people with a domain in which they may be partial to specific people and projects. It also explains the near universal intuition that redirecting a runaway trolley from its initial path, on which it will likely kill five innocent people, to a spur, on which it will likely kill one innocent person, is permissible, whereas a surgeon's cutting up one healthy patient in order to harvest his organs and thereby save five dying patients is not. The surgeon is appropriating his victim. The one redirecting the trolley is not, for she does not need his body, labor, or talents to save the five and would turn the trolley in his absence. ${ }^{16}$ The nonappropriation norm is one - and I believe the most plausible - conception of the socalled Doctrine of Double Effect. And it also may lie behind (and qualify) the common assumption that doing harm is morally worse than allowing harm.

Proponents of RI theories of justice are frequently called libertarians. ${ }^{17}$

16. The difficult case for the RI theorist is that of the trolley spur that loops around, so that whether the trolley proceeds down its initial course or down the spur track, it will hit and kill the five at precisely the same time. Killing the one, however, will stop the trolley or slow it enough to give the five time to escape. May one divert the trolley to the spur in such a case?

Frances Kamm has argued that one may, at least so long as one has some reason for so diverting the trolley that is independent of the presence of the one on the spur. See Frances M. Kamm, The Doctrine of Triple Effect and Why a Rational Agent Need Not Intend the Means to His End, 74 Supplement to the Proc. Aristotelian Soc'y 21, 21-39 (2000). I am not sure that I follow Kamm's reasoning, but I would agree with her if she means that one may divert the trolley so long as he would divert the trolley even if no one were on the spur. (Perhaps diverting the trolley would slow it just enough to give the five a few more seconds of life, or a less painful death, such that it would be worth the effort required to divert it.) What the nonappropriation norm forbids is counting the crushing of the one and its effects as a decisive reason for diverting the trolley.

17. For an excellent summary of various libertarian positions, see Peter 
Though I think that label is quite misleading, and that they are more accurately called nonappropriationists, I shall here also refer to them as libertarians.

Libertarians differ among themselves over how resources other than bodies, labor, and talent should be distributed. Those resources include land and other natural resources, of course, but also other things of value that people could enjoy in the absence of others. The liberty to engage in various activities is one such resource. I could drive my car as I pleased were you not around. You could walk in safety and without noise or fumes down the path where I wish to drive my car were I and my car not around. Likewise, I could paint my house green were you not around, whereas you could enjoy a view unspoiled by green houses were I not around.

I shall call the resources RI leaves open for distribution "common resources." Some libertarians - called left libertarians - would distribute the common resources equally. ${ }^{18}$ Of course, that is not as far "left" as left libertarians could go. A left libertarian could advocate distributing those resources in favor of people who are worst off in terms of what their bodies, labor, and talents can secure them. And there are other possible positions possible between this version of left libertariansim and the equal distribution position.

Right libertarians favor principles such as first possession for distributing the common resources that are less patterned than those favored by left libertarians. ${ }^{19}$ And then there are centrist libertarians who would distribute the common resources in proportion to how people would fare on their own, ${ }^{20}$ or who accept first possession principles but limit them by various conceptions of Locke's proviso that "enough and as good" shall be left for others to appropriate. ${ }^{21}$

I shall return to the distribution of common resources shortly. Here I

Vallentyne, Libertarianism, StAn. ENCYClOPEDIA PhIL., (Fall 2002) at http://plato. stanford.edu/entries/libertarianism.

18. See, e.g., Hillel Steiner, Original Rights and Just Redistribution, in LEFTLIBERTARIANISM AND ITS CRITICS: THE CONTEMPORARY DEBATE 74-99 (Peter Vallentyne \& Hillel Steiner eds., 2000). See generally LEFT-LiBERTARIANISM AND ITS CRITICS, supra.

19. See, e.g., Samuel Wheeler, Natural Property Rights as Body Rights, in LEFTLIBERTARIANISM AND ITS CRITICS: THE CONTEMPORARY DEBATE, supra note 18, at 22846.

20. See David Gauthier, Morals By Agreement 190-232 (1987).

21. See Eric Mack, Self-ownership, Marxism, and egalitarianism. Part I: challenges to historical entitlement, 1 POL., PHIL. \& ECON. 75, 75-108 (2002); Eric Mack, Self-ownership, Marxism, and egalitarianism. Part II: challenges to the selfownership thesis, 1 POL., PHIL. \& ECON. 237, 237-76 (2002); Eric Mack, The SelfOwnership Proviso: A New and Improved Lockean Proviso, 12 SOC. PHIL. \& POL'Y 186, 186-218 (1995). 
want to correct a misconception of some libertarians-usually, left libertarians - about just what are common resources subject to distribution under RI. I identified those resources as land and natural resources and also liberty to engage in activities and to enjoy experiences that would exist or that one could exercise or enjoy in the absence of those who are making conflicting claims on the resources. Some libertarians-Hillel Steiner, a left libertarian, is a prime example - believe that common resources include all land and natural resources. ${ }^{22}$ But that is incorrect.

Consider the following simple scenario. A and B are the only people. An apple tree is the only natural resource. (The apple tree and its apples can represent land and other natural resources, but also activities and aesthetic experiences.) A's and B's only talent is finding and picking apples. A is short. He can pick the apples only from the lower branches of the tree. B is tall and has difficulty bending over. He can pick the apples only from the upper branches of the tree. There are some branches of the tree that both A and B can reach, but there are some that only one or the other of them can reach.

Now apples are a natural resource. They are not anyone's body, labor, or talent. But in the scenario I have described, not all the apples are common resources subject to distribution. Why is that? It is because in the absence of B, A would not be able to harvest all of the apples, and likewise for B in the absence of A. A would only be able to obtain all of the apples if he could appropriate B's body and talents to harvest the highest apples that A cannot reach (and likewise for B with respect to the lowest apples). The only apples that are common resources are the apples that both A and B can reach. (Reaching, of course, refers not only to literally reaching, but is a stand in for such things as discovering previously undetected apples, or inventing new methods of harvesting otherwise inaccessible apples, such as step ladders and elongated shears. $)^{23}$

22. See Steiner, supra note 18 , at 78 .

23. Consider a different example. A and B have washed up on different islands. A's island is lush, with plenty of food and building materials available. A is able, without much exertion, to live a comfortable life. On the other hand, B's island is quite barren, and mere survival is a difficult and all consuming enterprise. Neither A nor B is capable of traveling to the other's island, although the currents make it possible for A to float food to B's island. However, given that fish swim between the two islands, A's fishing depletes the supply of fish available to B. In this scenario, the food and materials on A's island are not common resources up for division because they would not be 
Now this makes designating the domain of common resources to which RI applies quite complex, contrary to how some left libertarians seem to picture it. If there are five bushels of apples on the tree, and A can reach the bottom two, and B the top four, then only the one bushel of apples that is found in the area of overlap is a common resource. The bottom one bushel is A's alone. For B to obtain it without A's consent would require B to coerce A into using A's body, labor, and talents for B's benefit. And A is protected by the right against appropriation against such coercion. Likewise, the top three bushels are B's alone for the very same reason. Only the second bushel from the bottom (fourth from the top) is neither A's nor B's under the right against appropriation and is therefore a common resource up for distribution according to some distributive formula. ${ }^{24}$

As I said, the matter is complex because what is a common resource is not only determined by what one can physically obtain, but is also determined by individuals' discoveries and inventions. But the complexity is even greater because whereas A may have discovered a particular resource before B, B might have discovered it later, and in time to put it to some use. The reason why first possession rules seem arbitrary to many is that they appear to give a lifetime of benefit to the first possessor even if the runner up is only a few seconds behind. A resource that for some period is only one person's should be later regarded as a common resource if it would have been discovered by or otherwise have become accessible to others with the passage of time.

This is all that I shall say about common resources. Where libertarians divide - or at least should divide - is over how those resources should be distributed. Should they be distributed equally, for example, or should their distribution be sensitive to how well-off the various claimants are in terms of their noncommon resources? In our apple tree scenario, for example, should A get all of the bushels of common apples because A begins with only one bushel, whereas B has three? Or should A's share be determined by what would maximize

available to B in A's absence. (A will have to labor, even if minimally, to gather them and float them to B's island.) The fish, however, are common resources because they are available to each in the absence of the other.

Finally, consider the inhabitants of the planet Paradise, who are wealthy beyond our imagination, and who possess the technology to send their wealth to Earth, though we lack the technology to exploit Paradise's wealth on our own. In that scenario, there are no common resources, unless and until the Paradisians begin to exploit resources that we do have access to, or do something to disturb our aesthetic employment of the heavens.

24. That formula might be equal distribution, so that this bushel is divided equally between $\mathrm{A}$ and $\mathrm{B}$. But it might instead be whatever distribution maximizes the least advantaged (A's) position, which would result in A's getting the entire bushel. Or it might be divided in other ways that reflect A's and B's initial holdings. 
aggregate welfare, or what A would get in a bargaining game with B? There are all sorts of possibilities here, particularly if one takes account of the dynamic effects of various formulae for distributing common property. ${ }^{25}$ My aim here is not to recommend a distributive principle for common resources. It is only to describe what common resources are and how they fit into the RI picture.

I identified four problems faced by UI theories. And I said that RI theories make room for rights, for partiality, and for projects. RI theories also appear to be less demanding than UI theories. The discovery of a new planet with billions of people living in misery will create no new enforceable obligations under RI, much less an obligation to transfer resources and thereby descend into a state of misery ourselves.

RI theories do have their own serious problems, however. The first is a demandingness problem that I shall call the absolutism problem. RI is characterized by the right against appropriation, which right establishes the boundary beyond which impartial morality's jurisdiction does not extend. But the right against appropriation precludes not merely harvesting a kidney without consent to save another's life. It also precludes my touching your brow without your consent, even if doing so would save 1,000,000 lives. Touching your brow is, after all, an appropriation of your body. And the 1,000,000 lives would be doomed if you and your brow were not around, so that your refusal to consent does not make them any worse off than they would have been in your absence. Therefore, although it would be horrid of you not to consent, it appears that the right against appropriation forbids me to touch your brow, regardless of the catastrophe that will follow.

Libertarians quite naturally have sought to avoid this moral catastrophe objection by asserting that the absolutism of the right against appropriation gives way when the consequences are bad enough. They advocate a "threshold deontology," according to which the right against appropriation applies full bore up to some point at which the consequences of complying with the right's demand become so severe that the right

25. Robert Nozick and Richard Epstein point out the possible wealth-enhancing effects of welfare-insensitive rules of distribution, such as first possession rules and strong property rights. See RoBert Nozick, ANARCHY, STATE, AND UTOPIA 176-77 (1974); Richard A. Epstein, TAKings: Private Property AND the Power of EMinent DOMAIN 336-37 (1985). David Gauthier argues for a more equal division of both common resources and surpluses from exchange. See Eric Mack, Gauthier on Rights and Economic Rent, 9 SOC. PHIL. \& POL'Y 171 (1992). 
gives way to consequentialist concerns. ${ }^{26}$ I have elsewhere expressed my skepticism about this threshold deontology solution to the absolutism problem. ${ }^{27}$ In the absence of this or some other solution, however, the absolutism problem is potentially devastating for RI theories.

The second major problem of RI theories is related to the absolutism problem. It is what I shall call the desert problem. It reflects an unhappy gulf in RI theories between how wrong an act is and how bad it is.

Suppose that I can save 1,000,000 lives by touching your brow, but you refuse to consent to my doing so. And suppose, further, that I nonetheless undertake an arduous and quite risky set of maneuvers that ultimately enable me to surprise you and touch your brow. I thereby save the 1,000,000 lives. But under RI, what I have done is wrong because it violates your right against appropriation.

Ordinarily, when we knowingly violate, or attempt to violate or risk violating, others' rights, we deserve punishment. And ordinarily we believe that the amount of punishment we deserve tracks the seriousness of the wrong we commit. Finally, we ordinarily believe that the seriousness of the wrongs we commit reflects the importance of the interests protected by the rights we violate or attempt to or risk violating - that is, that wrongness tracks badness. But what punishment do I deserve in the case just described? I may perhaps deserve a reward, but do I deserve punishment?

Of course, touching your brow is a pretty minor thing, even if it violates your right against appropriation. But suppose with great effort and at great risk I transplant your kidney against your will in order to save another's life. Taking your kidney is serious. But do I deserve punishment, much less serious punishment? ${ }^{28}$

Indeed, I find that although I am quite sympathetic to the normal

26. See, e.g., NozICK, supra note 25, at 30.

27. Larry Alexander, Deontology at the Threshold, 37 SAN Diego L. Rev. 893, 893-911 (2000). The basic problem is that threshold deontology invites us to think of the right against appropriation as having a certain finite weight, which is why sufficiently bad consequences can overcome it. But if consequences and the right against appropriation can be weighed against each other, or otherwise compared in terms of greater or less than, it must be because they are comparable in terms of something measurable. Unfortunately, all they have in common in this respect are consequences, in which case UI will always outweigh the right against appropriation.

There are even versions of RI that would reject the very notion of a moral catastrophe beyond an individual catastrophe, given that even when 1,000,000 die, no individual suffers more than his or her own death. See, e.g., John M. Taurek, Should the Numbers Count?, 6 PHIL. \& PUB. AfF. 293 (1977). Attempts to account for the relevance of the number of affected people within an RI framework display the difficulty of the problem. See, e.g., Jens Timmerman, The individualist lottery: how people count, but not their numbers, 64 ANALYSIS 106 (2004).

28. For a glancing allusion to this problem, see Amartya Sen, Social Choice Theory and Justice, in CONSTRUCTIONS OF PRACTICAL REASON 158-61 (H. Pauer Studer ed., 2003). 
reaction to the surgeon-namely, that he may not kill one in order to save five with harvested organs - the question of whether he deserves punishment, and whether, if so, he deserves the same punishment that most killers deserve, I find perplexing.

Although the absolutism problem has received some philosophical attention, the desert problem remains, to my knowledge, essentially untouched. The problem is at root a reflection of RI's limited jurisdiction, which creates a discontinuity not present in UI theories. In the latter, the farther we deviate from what UI requires, the more wrong our act and the more punishment we deserve (assuming our UI theory makes room for desert). But under RI theories, an act can be RI wrong but otherwise UI mandated.

I do not know whether the desert problem has a solution. I surely have none to offer. But I am sure that the desert problem is one that RI theories, to be tenable, must ultimately solve.

A third problem for RI theories is children. Children are the products of their parents' labor, so why is it that parents do not own their children? Moreover, if parents have not made their children worse off by bringing them into existence, why do we suppose that parents must use their bodies, labor, and talents for their children's benefit?

A fourth problem for RI theories is whether they can justify a ban on selling oneself into slavery. Libertarians do believe that we are free to bind ourselves contractually to labor (or to donate, say, blood), and some believe that we can create thereby enforceable obligations that can be specifically enforced (as they were in the United States before peonage was outlawed, and as they are even today in the context of the military). ${ }^{29}$ It is only a short step from peonage and the military to voluntary slavery, morally speaking, but most libertarians do not endorse the complete alienability of the right against appropriation. If any line exists along the spectrum of degrees of alienation of this right, however, it requires a theoretical defense.

A fifth problem for RI theories, like the slavery problem, arises from those theories' endorsement of a right to make voluntary transfers of goods and labor as a corollary of the right of self-ownership (the right against appropriation). The right to transfer goods voluntarily is not itself derivable from the right against appropriation in any logically tight

29. There are, of course, practical problems with specifically enforcing affirmative obligations, but perhaps they will succumb to technological solutions. 
sense, but it seems to be a natural concomitant of the liberty that that right protects.

The difficulty is that RI theories never specify what the necessary and sufficient conditions are for a transfer to be voluntary and hence capable of changing parties' moral rights and duties regarding goods and actions. No transferor possesses all the information that might possibly bear on whether the transfer will subsequently be regretted. Nor is any transferor completely free of motivational pressures. (If he were completely free, his transfer would be unmotivated, which is not the paradigm of a voluntary transfer.) But when do ignorance or motivational pressures or both defeat voluntariness and hence the ability to transfer moral rights and duties? RI theories need to tell us.

The sixth problem for RI theories is an obvious one, namely, how to divide up the commons - those resources that are not subject to the selfownership right against appropriation. I pointed out that the logic of self-ownership restricts the definition of the commons to those resources that would be available to each of the competing parties in the absence of the others. In my apple tree example, the very highest and lowest apples would not be part of the commons for A and B. On the other hand, an apple that would not be part of the commons relative to $\mathrm{A}$ and $\mathrm{B}$ might be part of the commons relative to $\mathrm{A}$ and $\mathrm{C}$ or $\mathrm{B}$ and $\mathrm{C}$; for $\mathrm{C}$ might be able to reach some of the apples that $\mathrm{B}$ cannot reach but $\mathrm{A}$ can, or some of the apples A cannot reach but B can. So the introduction of more people complicates the identification of the commons-or more precisely, of the multiple commons.

Beyond this multiplicity of commons difficulty, which is endemic to $\mathrm{RI}$, there are the problems of allocating the commons that RI theories share with UI theories, namely, what currency (welfare, resources, and so forth) and what distributional formula (equality, priority, and so forth) to utilize. The extreme right libertarians attempt to avoid these problems by essentially denying the existence of a commons. Their denial is, however, implausible, especially when one considers, not resources like apples, but rather resources in the form of liberties. If A prefers loud music and B prefers peace and quiet, who has the liberty that the other must respect is an allocation of the commons problem every bit as much as who can get the apples in the middle of the tree. And it is not obvious how right libertarians' first possession principle applies in this case: if quiet preexists noise, does it win out?

Center libertarians generally would allow free appropriation of the commons by first appropriators - again, what does that mean in the case of music versus quiet? - so long as the first appropriators compensate others in a way that returns them to their pre-appropriation indifference curves. And left libertarians would divide the commons equally, or 
perhaps unequally, by giving larger shares to those worse off prior to the division. Both types need a metric to go with their formulae. And that will be as difficult for them as for UI theorists. Take the case of the apple tree again. Suppose A cannot reach the apples high on the tree, but he can see them. So even if he cannot eat them, he can enjoy them aesthetically. Are they then part of the commons relative to A and B? Must B compensate A when B picks them? Suppose A cannot see them but knows they are there and takes pleasure in that knowledge - just as people take pleasure in knowing that a wilderness area is unspoiled, even if they never plan to visit it or experience its unspoiled nature in any other way. ${ }^{30}$ Are the high apples now part of the A-B commons? Likewise, if sending the Martian lander will disturb people who believe Mars has religious significance and that the lander will desecrate it - even if those people cannot themselves observe Mars or the lander-must they be compensated for a taking from their commons, and if so, to what extent? Both UI and RI theories must handle cases such as these.

There is, finally, a problem of RI theories that may be less a problem internal to RI theories and more a problem with the coherence of those theories. I shall call this the lottery problem. Someone could argue that our sense that we have a right to, for example, our kidneys is a product of a failure of imagination. For imagine that prior to birth, human fetuses were featureless, and their physical and mental attributes were entirely the product of human choices regarding to whom various physical and mental characteristics should be distributed. (Imagine a warehouse containing both good and bad kidneys, from which the fetuses are distributed their kidneys according to some human plan.) If that is how we acquired our bodies, our willingness to labor, and our talents, would we then believe we had a "right" to them sufficient to block their redistribution according to a proper UI formula? ${ }^{31}$

If one thinks the answer is "no," one might conclude that RI theories should therefore be rejected, particularly if one thinks that the way we do obtain our attributes is relevantly similar to the imagined system. ${ }^{32}$

30. Laurence H. Tribe, Ways Not to Think About Plastic Trees: New Foundations for Environmental Law, 83 YALE L.J. 1315, 1346-48 (1974).

31. Richard Arneson first mentioned this view to me in conversation, although he could not recall its source in the literature. It has some affinity to views expressed by Derek Parfit. See, e.g., DereK Parfit, Reasons and Persons 321-47 (1984).

32. Cf. Anthony T. Kronman, Talent Pooling, in Human Rights 58-79 (J. Pennock \& J. Chapman eds., 1981) (discussing the implications of the idea that our talents should be treated as part of a common pool of resources). 
(Indeed, given the potential of genetic engineering and re-engineering, the actual similarity will undoubtedly become even greater.) I am not sure that this view is correct. But this potentially fatal critique of RI theories does call for a response.

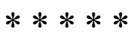

That is all I have to say. My aim, as I said, was to point out a major fault line in liberal political/morality that defines two quite different branches. Each branch has its own distinct problems. And each branch has its advantages, advantages that correspond to the problems of the other branch.

It is not my aim to minimize the importance of the intramural arguments within each of these branches. Within UI, the arguments over the proper currency and distributional formula are surely worth careful attention, particularly if UI theories as a group hold the high ground. The same is true of the disputes within RI among left, right, and center libertarians. But can UI theories meet the RI objections, and vice versa? That, too, is an important question, and in terms of what turns on it, the most important of all. 